skill mix in general dental practice, under the aspirations of better oral healthcare for patients. However, based on personal experience, many policymakers are ignorant or naive to the business of dentistry (the word 'profit' seems to be a taboo!), and are often reluctant to discuss these issues. I hope articles like this and further discussions are taken into consideration in future NHS contract developments and dental workforce planning in the UK.

B. Gupta

Wolverhampton

DOI: 10.1038/sj.bdj.2011.437

\section{QIPP, OR JUST Q?}

Sir, I congratulate Brocklehurst et al. on their informative paper, QIPP: cutting budgets or working smarter? ${ }^{\text {I }}$ imagine much of the profession will be dismayed at the approach of another acronym, so I shall try to be of assistance. I agree that Lord Darzi's NHS Next Stage Review ${ }^{2}$ points out aspects of quality that include effectiveness, patient experience and patient safety. Problems arise, however, when we move beyond the 'Q' in QIPP. Innovation has been variously defined, but my view is that innovation includes devices, systems, policies, programmes, products or services that are adopted/ adapted from other organisations, as well as those that are invented by the organisation itself; this approach has been supported by academics in the subject. ${ }^{3,4}$ Lord Darzi's report also emphasises the importance of innovation. ${ }^{2}$ It is my view that continual scoping for adoption and subsequent implementation of good innovation is essential to promote quality. We can therefore lose the 'I' from QIPP as it can be included in quality. Lord Darzi's ${ }^{2}$ report also emphasises the important role that prevention has to play in a quality service. We can therefore now lose the first 'P' as now this can also be included in quality. This leaves us with productivity. This is a measure of output. However, it is felt that it is much better to assess the dynamics of patient care in terms of effectiveness, ${ }^{5}$ which takes into account outcomes. The last 'P', for productivity, can therefore be dropped as inappropriate and it cannot be replaced by ' $E$ ' for effectiveness as this is included in quality. We are therefore just left with 'Q'. But in many respects we are still waiting for the 'A'.

\section{P. Kelly}

Weymouth

1. Brocklehurst $P$, Jones $C$, Tickle M. QIPP: cutting budgets or working smarter? Br Dent J 2011 210: 369-373.

2. Department of Health. High quality care for all. NHS Next Stage Review Final Report. Cm 7432. Norwich: TSO, 2008.

3. Damanpour F. Organizational innovation: a metaanalysis of effects of determinants and moderators. Acad Manage J 1991; 34: 555-590.

4. Mohr L B. Determinants of innovation in organizations. Am Polit Sci Rev 1969; 63: 111-126.

5. Donabedian A. An introduction to quality assurance in healthcare. pp 6-10. New York: Oxford University Press, 2003.

DOI: 10.1038/sj.bdj.2011.438

\section{DAYLIGHT ROBBERY}

Sir, these were not my words but those of my experienced and longstanding nurse when she heard what one dentist was going to charge to remove one intraoral suture.

I saw a patient under the NHS and the band 2 treatment I provided included the exam, scaling, X-rays, a class II (MO) amalgam and a surgical extraction of the upper right 7.

The treatment went without incident but as the patient lived some 20 miles away, I suggested they might find a local dentist who should remove the suture without charge.

The NHS practice she phoned couldn't see her for two weeks (maximum 60 seconds surgery time?) and a private practice wanted $£ 60$, yes sixty pounds to remove one suture! The patient returned to me.

I received a little over that amount for carrying out the band 2 treatment and it reminds me of sometimes the huge gulf in the cost of private and NHS care and yet if unfortunately a course of treatment came under the scrutiny of the courts, I would be expected to have provided the same standard of treatment whether I had done, for example, a molar endo and received around £70 to include other treatment, or it had been done privately at a cost of $£ 650$ which I know is a going rate of a specialist endodontic practice in my area. I wonder sometimes why I dare to provide NHS care but I do and have done very happily for over 34 years.

\section{P. Williams}

Lowestoft

DOI: 10.1038/sj.bdj.2011.439

\section{COUNCIL APPOINTMENTS}

Sir, my understanding of the current situation is that the GDC Council is appointed by the Appointments Commission, a Non-Departmental Public Body (NDPB, also known as a quango). Registrants no longer have the right to vote on who sits on the Council. I also understand that the Appointments Commission is due to be abolished. ${ }^{1}$ This was announced as part of the Government's cull on quangos in October 2010. In light of this, do any well informed colleagues know how the GDC Council will be appointed in the future? Will we be going back to the 'old' system?

R. Vasant London

1. Public bodies reform - proposals for change. http://www.direct.gov.uk/prod_consum_dg/ groups/dg_digitalassets/@dg/@en/documents/ digitalasset/dg_191543.pdf

DOI: 10.1038/sj.bdj.2011.440

\section{OSA AND MAD}

Sir, obstructive sleep apnoea (OSA) affects $1-2 \%$ of the population and occurs most often in overweight middle-aged men. OSA may result in excessive sleepiness, impaired intellectual performance, an increased risk of accidents and an impaired quality of life. ${ }^{1}$ Management of OSA can be divided into Continuous Positive Airway Pressure (CPAP) therapy, surgery and oral appliance therapy.

The use of Oral appliances, such as the Mandibular Advancement Device (MAD) has been shown to significantly improve nocturnal respiratory function and sleep quality in patients with OSA, even in patients with severe OSA. ${ }^{2}$ Thus MAD can be used as an alternative treatment modality regardless of severity because it is non-invasive, easy to manufacture and clinically effective. However, when considering the use of a MAD, the patient's dental health must be fully assessed. Insufficient teeth, pre-existing periodontal disease and TMJ pathology all have been shown contraindications to the use of MAD. ${ }^{3}$

We present a patient that developed mobility of his upper and lower anterior teeth following one week use of a MAD for treatment of OSA, despite the patient not having any clinical evidence of pre-existing periodontal disease 